\title{
Providing International Opportunities For Business Students: A Guide To Planning A Short-Term Study Abroad Program At Regional And Small Universities
}

Russell McKenzie, Southeastern Louisiana University, USA

Tará Lopez, Southeastern Louisiana University, USA

David Bowes, Southeastern Louisiana University, USA

\begin{abstract}
In recent years the perceived value and interest in participating in study abroad programs among college students has been increasing. Faculty who endeavor to develop study abroad programs face many challenges, particularly at smaller universities where resources may be very limited. This article offers recommendations to help faculty of regional and small universities who are considering developing a new direct-enrollment short-term program. The article addresses several pertinent issues including: the suitability of faculty, selecting a location, designing the course content, and post-trip evaluation.
\end{abstract}

Keywords: study abroad, Latin America, international education

\section{INTRODUCTION}

ऽ ince 1997, the number of U.S. students participating in international study abroad programs has increased dramatically. In fact, during that time, participation has increased by approximately $150 \%$. Between 2006 and 2007 (the last years for which reliable data is available), student participation in study abroad programs increased by $8 \%$, to a total of almost 242,000 students (Open Doors, 2008). While some of this increase is due to recognition by students of the importance of an international experience, much is due to an increase in the emphasis placed on international studies by universities and colleges. It is increasingly obvious that the ability to interact in a global environment is a requirement of many employers. This is especially true for students majoring in business disciplines. As such, the Association to Advance Collegiate Schools of Business (AACSB) has required participating schools to adopt an increasing focus on international or global issues. According to AACSB, "Every graduate should be prepared to pursue a business or management career in a global context. That is, students should be exposed to cultural practices different than their own" (AACSB, p13). This is a difficult task to accomplish within the confines of a traditional classroom setting.

In response, universities in general (and business schools in particular) have been increasing their roles and course offerings in study abroad programs. Study abroad programs provide students with unique opportunities to apply lessons learned in the classroom to real-world scenarios, while gaining exposure and familiarity with diverse cultures. This type of experiential education program is critical to the future success of today's graduates. According to Altbach (2002), the globalization of business school curriculums is not an option, but a necessity in order to achieve the goal of international sensitivity and awareness among graduates. 
Study abroad programs tend to be dominated, in absolute numbers, by larger institutions, with the top 20 programs primarily made up of large research universities (Open Doors, 2008). However, smaller regional universities are also contributing significantly to the number of U.S. students studying abroad. One of the difficulties faced by smaller programs is that they do not enjoy the economies of scale that larger programs experience. Therefore, the costs of providing these opportunities can be significantly higher. Many small schools and regional universities view "piggybacking" on existing programs, or purchasing a pre-packaged program, as the only viable means of providing study abroad opportunities to their students. But there are some tradeoffs associated with this approach. Some of these include a lack of control regarding program design, loss of student credit hours and tuition revenue for the institution, and lack of faculty development (Juban et al., 2006).

For those institutions that want to avoid "piggybacking" and follow the direct enrollment approach by developing a program internally, a rewarding study abroad is possible. It does require, however, a substantial amount of preparation, some good fortune, and some influential contacts. The purpose of this paper is to provide some guidance for first-time study abroad coordinators and faculty regarding the development of a successful program.

The following sections outline suggestions for developing a new direct-enrollment short-term study abroad program. While the suggestions presented here are merely recommendations, not requirements, they have proven to be important in our experiences (both good and bad) with a 3-year old program in Panama and on one author's study abroad experiences in Jamaica. Also, depending on the program's details, some issues may be more relevant than others. However the suggestions should apply in most regions of the world. For the sake of clarity, these suggestions are presented under separate headings. However, it is important to keep in mind that there is a great deal of interdependence between these issues.

\section{APPRAISING FACULTY SUITABILITY AND CONNECTIONS}

Faculty members planning to develop a direct enrollment study abroad program should begin with an honest evaluation of their individual suitability for such a program. Even the most dedicated instructor may not be well-suited for the issues he or she may encounter planning and conducting a study abroad program. The characteristics we have found to be most useful (and necessary) are 1) good organizational skills, 2) flexibility and willingness to adapt to difficulties, and 3) an immense reserve of patience. For both planning and conducting a study abroad program, the ability and willingness to adapt and deal with unforeseen problems is critical. As a program coordinator, the process should be viewed as an exercise in product development. If it is not developed properly, and doesn't adjust easily to adversities, it will likely not survive.

While planning and conducting our very first trip to Panama, we encountered many problems that would make many faculty seriously reconsider continuing a study abroad program. Approximately one week before departure, our primary hotel decided to more than double its rates. Since this was our first trip, we had no reserve funds and therefore had to scramble at the last minute to find a comparable hotel at our budgeted price. We had several stressful days until our hotel was secured. On the other hand, sometimes unexpected changes open up an opportunity for an even better experience than originally planned. Also during our first trip, one of our scheduled speakers did not show up. Presented with the dilemma of what to do, we decided to take a trip to a nearby town on the Caribbean coast of Panama. It ended up being one of the most memorable experiences of the trip.

Personally having a connection to the selected study abroad location, or working with someone who has a connection to the location, can greatly enrich the study abroad experience. These connections can range from family and friends to colleagues to alumni to affiliated institutions. Personal insights and shared stories from someone with local connections can make the experience much more personal for the students. Utilize any personal and/or professional contacts that may be able to assist with planning and conducting the program can also be a means of reducing some of the difficulties and costs associated with study abroad. These local resources can often help directly, or at least provide valuable advice. Establishing these connections and nurturing them can benefit your program and students significantly. 
We were fortunate to have two excellent connections for the country of Panama. One is a family member who is an administrator at a Panamanian university. The second is a graduate of our university's MBA program whom we did not know and contacted specifically to provide guidance for our first trip. Both contacts have been invaluable for the program. They have organized speakers, recommended accommodations, and helped us make decisions. In addition, they have shared their personal stories and viewpoints with our students.

\section{SELECTING A LOCATION}

\section{Attractiveness to Students}

There are several issues to consider when choosing a destination for a study abroad program. Not the least of which is the attractiveness of the destination as a place of interest to potential students. According to Open Doors (2008), Europe is the number one destination, with France, Spain, Italy and the UK occupying the top four spots, and all European destinations accounting for $57 \%$ of all U.S. students abroad. While Europe dominates all other locations as the most frequent destination, it may not be the best choice for your program.

While a study abroad program should be an enjoyable experience, it should not be promoted or viewed as a "vacation". Thus, vacation destinations are not necessary for a successful program. Ideally, there should be some connection between the destination and the origin. This can be in terms of culture, economic linkages, institutional or personal contacts or interests. The more relevant the experience in a particular destination is to the overall educational objectives, the more the students will benefit.

Although Panama is not among the most popular destinations for study abroad, most of our students developed a feeling of a connection with the country and the majority have said they want to go back again. We believe Panama works well for our program for several reasons. Most importantly, we have relationships with locals who can arrange for high quality, relevant speakers. We feel that another factor is our efforts to engage students with locals and truly experience the local culture. One way we accomplish this is through the design of our assignments which is discussed in a subsequent section.

\section{Focus}

Another consideration when selecting a location is the specific focus of the study abroad program. It is important to ensure that the destination chosen provides ample opportunities for meeting the program's intended objectives. A program focusing on eco-tourism would obviously be more relevant in Panama or Costa Rica than in Paris. Likewise, a program focused on large multi-national corporations may be better suited for Asian or European countries than for Jamaica. This match in objectives and opportunities is important.

If the program is a product of a department or college or school with a unifying or dominant area of interest, destinations that enhance that interest would be attractive. If it is the product of a faculty member or group of faculty with common interests and expertise, then destinations that expose and foster development in those areas would be appropriate. The goal of study abroad programs in general is to provide students with experience applying lessons from the classroom in an international environment. The more closely the two experiences coincide, the more rewarding the trip may be for the students.

\section{Costs}

One should also consider the costs and financial viability associated with conducting a study abroad program at different destinations. Within the subset of suitable countries, costs may differ substantially, depending on available accommodations, local and international transportation, provisions for meals, and other relevant expenses. While each involves its own difficulties when planning for a large group, all must be done within a budget - both in terms of finances and time. This budgeting requirement implies that there must be tradeoffs. We have found that relevant and meaningful activities are often financially prohibitive due to logistical difficulties. A lack of accommodations and transportation issues are often limiting factors. The difference between good choices and poor choices may be the success or failure of program. 
Depending on your destination, one such tradeoff (in terms of finances) will likely be between lodging costs and transportation costs. Often, adequate lodging in the most desirable location is more costly, while transportation costs are less. On the other hand, adequate lodging, somewhat removed from the most desirable location tends to be less expensive. However, this is often offset by increases in transportation costs. In addition, it should be noted that the additional cost of a remote location (that is relative to lectures, tours, events, etc.) is the increased travel time that must be allowed.

When selecting lodging, keep in mind that "adequate" is a relative term and may not compare to what one would consider to be adequate by U.S. standards. We recommend choosing lodging arrangements that are safe and sanitary (to the extent possible), but forgo the upscale options. If traveling about and moving from place to place, we have found it to be beneficial to postpone upgrades in lodging until the last leg of the trip. We have found that setting the bar low during an earlier portion of the trip, and stepping it up later in the trip provides a sense of accomplishment and excitement among the students, and it keeps the momentum of the trip moving in an appropriate direction.

If your location requires private transportation, such as a bus, establish concrete arrangements early. Determine when the services will be required and for what duration and distance, and make sure those details, as well as an exact price, are covered in your contract. In destinations with well established public transportation, this may not be critical. However, many destinations (especially developing countries) do not have reliable public transit infrastructure. In those cases, failure to secure dependable private transportation may interfere with scheduled activities.

Encountering major logistical problems once you reach the host country is possibly the greatest concern of a study abroad coordinator. There are likely few worse feelings than arriving at your destination with a group of students, only to find out that your lodging arrangements are not going to be honored. It is wise (if not critical) for faculty to always have an alternative, or at least some resources to call on in the event of major logistical issues. In the case of lodging accommodations or transportation - contact information for a low-cost alternative and a reserve of emergency funds will help in dealing with the issues. The key is to always be prepared for emergencies and have a plan B.

\section{DESIGNING THE COURSE CONTENT}

Once the primary focus and location are established, the specifics of how that focus will be carried through the program must be determined. Our approach, based on that posited by Budden, et al (2005), Baraya, et al (2005), and others, is to divide the program into two parts - pre- and post-trip lectures and in-country activities. The pre-trip lectures address important issues, such as discussing expectations, schedule, and activities, but they also include program-specific lectures on academic concepts to be experienced. Post-trip meetings are reserved for exams, presentations, and reflection. However, it should be noted that post-trip meetings are sometimes difficult. Our experience has shown that without clear expectations regarding the importance of the post-trip component, students are often unable to attend these meetings. Even if the reasons are legitimate, such as internships or jobs in other locations, lack of participation by some students diminishes the experience for the other students.

Arranging in-country lectures, activities and events is often challenging. One popular and meaningful approach in business programs is to rely on knowledgeable and prominent members of host-country business and government for much of the academic content in the program. This often takes the form of invited speakers and onsite tours of businesses and government institutions. According to Duke (2000), and verified by our experiences, this often proves to be the most difficult task. Finding "someone" to speak or "somewhere" to go is not that difficult. However, students often have higher expectations than a program coordinator may anticipate. They expect tours that are relevant and interesting, and speakers who are knowledgeable and insightful. We work closely with our local contacts to select the best speakers and tours for our students. Each year we evaluate the speakers and tours and decide which ones to include in the program the following year. We have found that attention to these concerns pays off in terms of a quality experience for the students. 
In addition to these activities, faculty delivered content is very useful for tying classroom lessons and study abroad experiences together. Faculty should be mindful that the mixture of possible lectures and tours often requires some clarification to illustrate how the different experiences are meaningful and related to program objectives. It is also helpful to keep in mind that students have different learning styles and the more diverse the learning environment the more they learn (Baraya, et al, 2006). While some students are better served by lectures, others may relate more to tours or activities. The diversity in learning styles means that faculty members must work to integrate different methods.

Students also expect, and benefit from, exposure to the culture of the host country. The top three common complaints reported by Koernig (2007) indicated that study abroad students felt there was too much academic content. The top three positive comments indicated that the most enjoyable experiences were cultural exploration and activities. While academics are important, cultural exposure and awareness may be as rewarding. Thus, balancing the academic content with cultural activities and free-time is a delicate, but important task. We have found that a couple of intense lecture days at the beginning of the program, offset by several light days and free time later in the trip seems to work well. Students are highly motivated at the beginning of the trip, but their focus and energy starts to wane as the trip progresses. Therefore, having a heavier lecture load at the beginning of the trip and then lightening the load as the end approaches, takes advantage of students' level of focus and energy throughout the trip. In addition, incorporating substantial academic content into the pre- and post-trip meetings allows more time for cultural exploration. We have also found that it works well to schedule lectures in the morning and tours in the afternoon, when possible. Our experience is consistent with that of Koernig (2007) who recommended that 40\% academic, $40 \%$ cultural and $20 \%$ individual exploration is a good distribution of activities for the in-country portion of the trip.

In addition to the scheduling of lectures and tours, we have also found that giving students specific, directed assignments (Koernig 2007) helps to achieve the balance between academic, cultural, and individual exploration time. We provide students with a list of specific assignments to complete. Included in the list are several assignments required of all students and other subsets of assignments, from which students can pick and choose, depending on their individual interests. Each assignment carries a specific point value, and students are expected to accumulate points during the trip, which contribute to their grade for the courses. The assignments are designed to force students to think about the academic focus of the program while at the same time immersing them in the culture.

One of our students' favorite assignments requires them to visit a local elementary school. Students are asked to purchase appropriate supplies for any elementary class, and to present them to the students. During this activity students are encouraged to document their experience in writing and photos, and to pay particular attention to their observations regarding several issues:

1. the market conditions and comparisons of goods purchased;

2. the quality of school facilities, availability of supplies, perception of education;

3. comparisons of the overall socio-economic conditions, infrastructure, and cultural norms to those in the U.S.

Upon completion of the activity, students must prepare a written summary of their experience and present an overview to the rest of the students.

This assignment has several the positive attributes. It exposes students to the business concepts of product availability and pricing by expecting them to purchase school supplies on their own. It forces them to communicate with locals to purchase the items and secure transportation to the school. It gives students the opportunity to see the local educational system first hand. This is an easy comparison for the students to make because obviously they have experience in the US educational system, so they tend to be very observant about differences in the local schools. The assignment ties the in-country experience to the topics of the study abroad courses. In this case, the courses are in marketing and economics. The assignment also requires students to reflect on the experience as they write their summary and in their journal which is a separate assignment. Reflecting on the experience forces students to think critically about it and to accept greater responsibility for learning. Students' reflections help inform and 
guide faculty in planning and teaching in future study abroad programs. The students also experience a sense of accomplishment for having completed the task on their own.

\section{POST-TRIP EVALUATION AND REFLECTION}

An issue of increasing importance is ensuring the objectives of any study abroad program are being met and that study abroad courses incorporate an appropriate degree of rigor. These programs are coming under more scrutiny by administrators and accrediting bodies, as some may view study abroad as simply a vacation with course credit. In our experience, this is particularly an issue in colleges of business. Faculty and coordinators are expected to develop acceptable course objectives or adopt an institution's academic objectives and implement a means of measuring student performance to determine if those objectives are being met.

During the planning phase for a study abroad trip, the coordinators must determine how to measure student learning. Appropriate instruments typically include evaluation of student projects or assignments, presentations, research papers and exams. We incorporate all of these methods. Although research papers are only required of graduate students. For these methods to be most useful, the coordinator must do a thorough job communicating his/her expectations of student performance on each. Being very specific and/or providing samples of good work goes a long way toward helping students understand what is expected of them. As with any course, there is no perfect model for evaluating student performance. Each faculty member must evaluate standards and student expectations that are relevant to his or her own program.

During the travel abroad portion of the program and immediately upon return, faculty should conduct a critical examination of the successes and failures of the program. Reflecting on the activities and events with a focus on how well the plans achieved the goals that were set, provides a great starting point for next year's trip. Identifying problems with student activities, logistics, academic components and one's own decisions can make subsequent trips better than those before.

\section{CONCLUSION}

Increasing globalization in the marketplace is generating significant growth in student participation in study abroad programs around the world. Providing these opportunities at small regional universities presents some unique challenges. Without the economies of scale enjoyed by large-scale programs, small direct-enrollment programs must pay particular attention to the details that provide the most "bang for the buck".

Planning and conducting a study abroad program is certainly an arduous task, but one that, when done well, can significantly add to the educational experiences of participating students and faculty. In an increasingly global marketplace, students who have more exposure to and awareness of different cultures have a distinct advantage. Designing a business oriented study abroad program presents some interesting challenges that are somewhat unique. However, with some careful planning, the ability and willingness to be flexible and a great amount of patience, a rewarding and successful program is possible.

\section{AUTHOR INFORMATION}

Russell McKenzie is an Assistant Professor of Economics at Southeastern Louisiana University in Hammond, Louisiana. Teaching interests include environmental economics, urban and regional economics, and economics of social issues. His research and publication topics include housing and urban/regional economics incorporating GIS into traditional economic analysis, and water resource economics. He has published in numerous journals including the Journal of Real Estate Finance and Economics, Papers in Regional Science, Applied Economics Letters, and Economics of Education Review, among others. Professor McKenzie received his Ph.D. in Economics from Oklahoma State University.

Tará Burnthorne Lopez is an Assistant Professor of Marketing at Southeastern Louisiana University. She has published in the Journal of Business Research, Journal of Personal Selling and Sales Management, the Journal of Marketing Education, and the Journal of Marketing Theory and Practice, among others, and has had papers 
accepted at numerous regional and national conferences. Tará completed her doctoral work at Louisiana Tech University, and has held positions at the University of Southern Mississippi and Mississippi College.

David Bowes is an Associate Professor of Economics at Southeastern Louisiana University in Hammond, Louisiana. His research interests include urban land use, urban transportation, and environmental quality. He has published papers in the Journal of Urban Economics, Urban Studies, Economic Development Quarterly, and College Teaching Methods and Styles Journal. Professor Bowes Received a Ph.D. in Economics from Georgia State University.

\section{REFERENCES}

1. Altbach, P., 2002. "Perspectives on Internationalizing Higher Education". Center for International Higher Education, Boston College, Boston, MA.

2. Association to Advance Collegiate Schools of Business (AACSB). 2009. Eligibility Procedures and Accreditation Standards for Business Accreditation. Retrieved October 19, 2009, from http://www.aacsb.edu/accreditation

3. Baraya, A., M. Budden, and R. Juban, 2005. "Enhancing Business Students' International Capabilities Through Global Education Programs". Journal of Business \& Economics Research, 3(6), 45-50.

4. Budden, M., A. Baraya, and R. Juban, 2005. "Developing an MBA Study-Abroad Program at Southeastern Louisiana University". Business Communication Quarterly, 68(2), 233-236.

5. Duke, C., 2000. "Study Abroad Learning Activities: A Synthesis and Comparison". Journal of Marketing Education, 22(2), 155-165.

6. Juban, R., A. Baraya and M. Budden, 2006. "Going it Alone: Developing an Independent Study Abroad Program”. Journal of College Teaching \& Learning, 3(2), 61-66.

7. Koernig, S., 2007. "Planning, Organizing, and Conducting a 2-Week Study Abroad Trip for Undergraduate Students: Guidelines for First-Time Faculty". Journal of Marketing Education, 29(3), 210-217.

8. Open Doors. 2008. Fast Facts. Retrieved October 30, 2009, from http://opendoors.iienetwork.org 
NOTES 